\title{
Improving the Potential of Agricultural Areas for Development of Agrotourism: A Case Study of Ban Mor Village, Sam Sung District, Khon Kaen province
}

\author{
Thirachaya Maneenetr \\ Director of Center for Asia-Pacific Tourism Research, Faculty of Management Science, Khon Kaen University \\ Email: thirachaya@kku.ac.th \\ Thanh Ha Tran \\ Student in Master Degree of Tourism Management, Faculty of Management Science, Khon Kaen University \\ Email: cholly.pen@gmail.com
}

Doi:10.5901/mjss.2014.v5n23p533

\begin{abstract}
This article aims to study tourists' opinions and tourists' demand for agrotourism and guidelines to improve agrotourism in Ban Mor Village, Sam Sung District, Khon Kaen Province. This is an organic agricultural village which applies the Sufficiency Economy Philosophy as a core fundament in the farmers' livelihood. Quantitative and qualitative methods were applied and the results show that tourists' demand for agrotourism, in terms of accessibility, was at the highest level while attitudes, attractions, accommodations, activities, amenities, and advertising were all at the high level. Appropriate guidelines were proposed to improve the agricultural area and to develop agrotourism in this research area. These include 1) improving Homestay in Ban Mor Village according to the Homestay standard in Thailand 2) improving facilitates to respond to tourists' demands 3) promoting agrotourism in the Ban Mor Village and 4) establishment of a local agricultural learning center in Ban Mor village.
\end{abstract}

Keywords: Agrotourism, Components of tourism destination

\section{Introduction}

Ban Mor Village is an agricultural village in Sam Sung district of Khon Kaen province, in the northern region of Thailand. This village applies the Sufficiency Economy Philosophy developed by the King of Thailand as a fundamental concept in the farmers' livelihood. The Sufficiency Economy Philosophy highlights a balanced way of life (Mongsawad, 2010), and an adequate social and economic foundation to attaint sustainable development (Chalapati, 2008). Transferring from traditional agriculture to organic agriculture is a key turning point based on the concepts of the Sufficiency Economy Philosophy. This is because organic agriculture focuses on environment conservation (Ritson \& Oughton, 2006) and healthy products for consumers (Walley et al., 2009). At the present, Ban Mor Village is well known for organic vegetable production and also as an emerging agrotourism destination. In addition to its main income from farming; tourism is a crucial part in the rural economy to achieve an additional wide range of economic benefits such as increasing employment and enhancing income (Yang et al., 2010).

Agrotourism is a tourism product which is developed to meet tourists' needs (Xu, 2010) and offers an integrated experience to consumers (Buhalis, 2000). With regard to tourism development, a key question is what makes a memorable and successful experience for tourists (Xu, 2010). In terms of agrotourism in Ban Mor Village, the researchers focused on the topics of tourists' opinions and tourists' demand for agrotourism and the proposing of guidelines to improve agrotourism. In this respect, two questions were raised 1) What are tourists' opinions and tourists' demands for agrotourism in Ban Mor Village, Sam Sung District, Khon Kaen province and 2) What guidelines, should there be to improve agrotourism in Ban Mor Village, Sam Sung District, Khon Kaen province.

\section{Objectives of the Study}

(1) To study tourists' opinions and tourists' demand for agrotourism in Ban Mor Village, Sam Sung District, Khon Kaen Province.

(2) To study guidelines to improve agrotourism in Ban Mor Village, Sam Sung District, Khon Kaen province. 


\section{Literature Review}

\subsection{Agrotourism}

Agrotourism or agritourism is a synonym definition which is the phenomenon of attracting people onto agricultural holdings (Evans \& Ilbery, 1989) which has been recognized world-wide since the early twentieth century (Wicks \& Merrett, 2003). Agrotourism is a set of activities in which people link travel with products, services and experiences of agriculture (Maetzold, 2002). Arroyo et al (2013) defines agrotourism as including agricultural settings, entertainment, farming and education. It is consistent with Flanigan et al. (2014) who proposed that the key characteristics of agrotourism include a working farm, contact with agricultural activities which are organized by farmers and authenticity of tourists' agricultural experiences. Therefore, agrotourism is more than a tourism product, but it is also a journey for new sensations, and positive behavior in relation to the environment, the agricultural community and their culture (Lopez \& Garcia, 2006).

Agrotourism brings to tourists unique experiences during the time they spend in rural areas. They gain respect for the local customs, local culture and enhance their awareness of the environment and natural products (Lopez \& Garcia, 2006). Tourists are also looking for facilitate tourism in terms of agricultural areas such as accommodations that ensure peace and rest (Halfacree, 1993), traditional food, information on agrotourism destinations, safety and security and basic infrastructures (Kumbhar, 2009).

With regard to the local community or farmers, agrotourism is very important to rural communities. It seems to be a mechanism to stimulate rural development. Agrotourism intends to obtain quality of living for rural communities through stimulation of the farmer's business (Tew \& Barbiere, 2012), promoting and creating added value to local products (Zoto et al., 2013) and increasing awareness and preservation of local customs and unique cultural traits (Ollenburg \& Buckly, 2007).

In terms of sustainable tourism, tourism activities should be based on ethical values while taking into account the economic, environmental and social impact (Goodwin \&Francis, 2003). That is why organic agrotourism was created as an innovative agrotourism. Organic agrotourism combines organic culture which focuses on healthy food with high standards (Walley et al., 2009) and ecotourism to provide acceptable recreation opportunities without destroying the environment (Kuo \& Chiu, 2006).

\subsection{Components of tourism destinations}

A local tourism destination is a physical space where tourists choose to stay to experience certain features or attractions (Leiper, 1995). A destination contains a number of basic elements which attract visitors to the destination and which satisfy their needs on arrival. There are attractions, public and private amenities, accessibility, human resources, image and character, and price (World Tourism Organization: UNWTO, 2007). Buhalis (2000) also suggests that there are six core components of a destination which include: attractions, accessibility, amenities, available package, activities and ancillary services. These are basic factors which have significant impact on the travel-decision process. The component that is a fundamental element in a tourism destination is to incorporate tourism products which are capable of meeting tourists' demands and to create memorable experiences for tourists $(X u, 2010)$. This seems to be the draw factor to motivate tourists to select a destination.

With regard to tourism management, local residents' attitudes and perceptions should be considered. Many tourism researchers believe that planners and entrepreneurs must take the view of the host community because their attitudes and perceptions can have an influence on the successful development of current and future tourism programs (Wang et al., 2009; Williams \& Lawson, 2001).

Lastly, advertising also plays an important role in informing, seeking and prompting tourists regarding tourism products at destinations (Morrison, 2013). Advertising can also be a means to educate tourists about appropriate behaviors at sensitive sites and to emphasize the cultural or spiritual significance of the destination (Ely, 2013).

In terms of this study, the researchers applied seven (7) aspects including Attitudes, Attractions, Accessibility, Accommodations, Activities, Amenities, and Advertising to identify tourists' demand for agrotourism in Ban Mor Village, Sam Sung District, Khon Kaen province.

\section{Methodology}

To ensure the study was objective, the researcher employed the Mixed Method approach as shown below: 


\subsection{Population and sample}

The participants in this study were as follows:

(1) Thai tourists and international tourists who visited Khon Kaen province. According to the Department of Tourism (2012), there were 2,048,346 tourist arrivals to Khon Kaen province. Using Yamane's formula (1973) and a 95\% confidence level, the researcher calculated the sampling size as 423 participants.

(2) Ten experts who have long term experience on agrotourism and agro areas management in Ban Mor Village, Sam Sung District, Khon Kaen province. There were academics, tourism entrepreneurs, representatives of involved public organizations and local philosophers.

\subsection{Study design}

Research data was conducted from January 2012 to May 2013 which is described in detail as shown below:

(1) For the quantitative data, questionnaires were created which consisted of three parts 1) Demographic information of the tourists 2) Tourists' opinions on agrotourism in Ban Mor Village, Sam Sung District, Khon Kaen province. 3) Tourists' demand for agrotourism in Ban Mor Village, Sam Sung District, Khon Kaen province.

In terms of statistical analysis of the data, the mean, standard deviation and chi-square test were used.

(2) For the qualitative data, a focus group discussion was organized. Ten experts which included academics, tourism entrepreneurs, representatives of involved public organizations and local philosophers discussed ways to design appropriate guidelines to improve agrotourism. Data analysis was used as a descriptive analysis.

\subsection{Research area}

Ban Mor Village in Sam Sung District of Khon Kaen province is an agricultural village which applies the Sufficiency Economy Philosophy in rural development step-by-step. There are 196 households which focus on organic farming (Sam Sung District Agricultural Extension, 2012). Ban Mor Village is well-known as an agricultural area which produces organic vegetables in Khon Kaen Province and is also emerging as an agotourism destination, too.

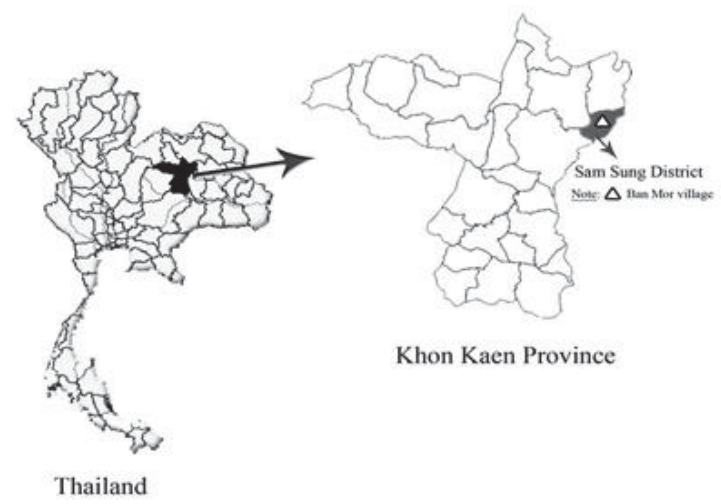

Figure 1. Research area

\section{Result}

\subsection{Tourists' opinions on agrotourism in Ban Mor Village, Sam Sung District, Khon Kaen province.}

With regard to organic agrotourism in Ban Mor Village, the majority of tourists were interested because this type of tourism encourages preserving the environment and natural resources. There were $35.2 \%$ of the tourists who believed that organic agrotourism had a positive impact on the local community by giving increasing support to the economic community.

An average of $42.6 \%$ of the tourists knew about Ban Mor Village from their relatives or their friends and $32.2 \%$ had a positive impression of the agrotourism destination in Ban Mor Village because of friendship with the local community. Those who would like to learn how to plant organic vegetables were $29.6 \%$ and $41.6 \%$ of the tourists thought that they 
enhanced their awareness of farmers' livelihoods. Additionally, $43.3 \%$ of the tourists believed that applying the Sufficiency Economy Philosophy through tourist activities increased the significance and meaningfulness of organic agrotourism in Ban Mor Village. Regulatory compliance with the agriculture village is the role of tourists during the time they spend at the agrotourism destination. Furthermore, $42.6 \%$ of the tourists sought tourism information on Ban Mor Village via the Internet. Finally, $49.6 \%$ of the tourists commented that Ban Mor Village should improve accommodations to facilitate to tourists.5.2 Tourists' demand for agrotourism in Ban Mor Village, Sam Sung District, Khon Kaen Province.

Table 1: Tourists' demand for agrotourism in Ban Mor Village, Sam Sung District, Khon Kaen province.

\begin{tabular}{|c|c|c|}
\hline \multirow{2}{*}{$\frac{\text { Item }}{\text { Attitudes }}$} & \multicolumn{2}{|c|}{$\bar{x}$ S.D. Interpre-tation } \\
\hline & & \\
\hline Readiness of local community in supporting agrotourism & 4.420 .54 & Highest \\
\hline Positive attitude and friendliness of local farmers to tourists & 4.140 .55 & High \\
\hline Establish relationships between local farmers and tourists & 4.060 .66 & High \\
\hline \multicolumn{3}{|l|}{ Attractions } \\
\hline Environmental landscape management & 4.570 .55 & Highest \\
\hline Establish an organic agrotourism learning center & 4.610 .71 & Highest \\
\hline Several types of organic vegetables & 4.030 .65 & High \\
\hline Telling-stories about farmers' livelihoods & 3.640 .58 & High \\
\hline \multicolumn{3}{|l|}{ Accessibility } \\
\hline Convenient access to the agrotourism destination & 4.590 .50 & Highest \\
\hline Safe paths to the agrotourism destination & 4.480 .52 & Highest \\
\hline Improving road conditions & 4.450 .61 & Highest \\
\hline Parking zones & 4.340 .67 & Highest \\
\hline $\begin{array}{l}\text { Clearly labeled signposts for the agrotourism destination } \\
\text { Accommodations }\end{array}$ & 4.260 .57 & Highest \\
\hline Taking into account the quantity of accommodations and the number of tourists & 4.130 .68 & High \\
\hline Accurate description and fair pricing & 4.020 .66 & High \\
\hline Facilitate the tourism destination & 3.900 .63 & High \\
\hline Several types of accommodations (Homestay/camping zones) & 3.840 .64 & High \\
\hline Arranging and cleaning the lodgings & 3.630 .70 & High \\
\hline \multicolumn{3}{|l|}{ Activities } \\
\hline Sharing of experiences between local farmers and tourists through agrotourism activities & 3.990 .71 & High \\
\hline Agricultural knowledge training & 3.860 .53 & High \\
\hline Tourist activities based on the Sufficient Economy Philosophy & 3.810 .74 & High \\
\hline Diversity of agrotourism activities & 3.730 .59 & High \\
\hline \multicolumn{3}{|l|}{ Amenities } \\
\hline Improve infrastructure for tourists(electric/water supply) & 4.260 .67 & Highest \\
\hline Vehicles to use for traveling around the agrotourism destination & 4.330 .62 & High \\
\hline Explanation on agrotourism from local guides that are farmers & 4.170 .64 & High \\
\hline $\begin{array}{l}\text { Local cuisine from local ingredients } \\
\text { Advertising }\end{array}$ & 3.970 .64 & High \\
\hline Convenient tracking of agrotourism information & 3.890 .69 & High \\
\hline Diversified channel of advertising & 4.440 .54 & Highest \\
\hline Reliability of agrotourism information & 3.820 .70 & High \\
\hline Total & 4.100 .13 & High \\
\hline
\end{tabular}

Table 1 shows this study's results regarding tourists' demand for agrotourism in Ban Mor Village, Sam Sung District, Khon Kaen Province. Each aspect of these findings is interpreted below:

(1) For attitudes, readiness of the local community in supporting agrotourism is at the highest level (Mean $=4.42$, S.D. $=0.54$ ). Positive attitudes and friendliness of local farmers to tourists is at the high level (Mean $=4.14$, S.D. $=0.55$ ). Establish relationships between local farmers and tourists is also at the high level (Mean $=4.06$, S.D. $=0.66)$.

(2) For attractions, environmental landscape management is at the highest level (Mean $=4.42$, S.D. $=0.54$ ). Establish an organic agrotourism learning center is at the highest level (Mean $=4.61$, S.D. $=0.77$ ). Continual monitoring and quality control of agrotourism is at the high level (Mean $=3.81$, S.D. $=0.75$ ). Several types of 
organic vegetables is at the high level (Mean $=4.03$, S.D. $=0.65$ ). Telling-stories about farmer's livelihoods is at the high level (Mean $=3.64$, S.D. $=0.58)$.

(3) For accessibility, convenient access to the agrotourism destination is at the highest level (Mean $=4.50$, S.D. $=$ 0.50). Improving road conditions is at the highest level (Mean $=4.45$, S.D. $=0.61$ ). Parking zones is at the highest level (Mean $=4.34$, S.D. $=0.67$ ). Clearly labeled signposts for the agrotourism destination is at the highest level (Mean $=4.26$, S.D. $=0.57$ ). Safe paths to the agrotourism destination is at the highest level (Mean $=4.48$, S.D. $=0.52$ ).

(4) For accommodations, several types of accommodations (Homestay/camping zones) is at the high level (Mean $=3.84$, S.D. $=0.64)$. Arranging and cleaning the lodgings is at the high level (Mean $=3.63$, S.D. $=0.70)$. Facilitate the tourism destination is at the high level (Mean $=3.90$, S.D. $=0.63$ ). Taking into account the quantity of accommodations and the number of tourists is at the high level (Mean $=4.13$, S.D. $=0.68$ ). Accurate description and fair pricing is at the high level (Mean $=4.02$, S.D. $=0.66$ ).

(5) For activities, diversity of agrotourism activities is at the high level (Mean $=3.84$, S.D. $=0.64$ ). Agricultural knowledge training is at the high level (Mean $=3.86$, S.D. $=0.53$ ). Tourist activities based on the Sufficiency Economy Philosophy is at the high level (Mean $=3.81$, S.D. $=0.74$ ). Sharing of experiences between local farmers and tourists through agrotourism activities is at the high level (Mean $=3.99$, S.D. $=0.71$ ).

(6) For amenities, improve infrastructure for tourists (electric/water supply) is at the highest level (Mean $=4.26$, S.D. $=0.67)$. Local cuisine from local ingredients is at the high level (Mean $=3.97$, S.D. $=0.64)$. Explanation on agrotourism from local guides that are farmers is at the high level (Mean $=4.17, \mathrm{~S} . \mathrm{D} .=0.64)$. Vehicles to use for traveling around the agrotourism destination is at the high level (Mean $=4.33$, S.D. $=0.62$ ).

(7) For advertising, diversified channel of advertising is at the highest level (Mean $=4.44$, S.D. $=0.54$ ). Convenient tracking of agrotourism information is at the high level (Mean $=3.89$, S.D. $=0.69$ ). Reliability of the agrotourism information is at the high level (Mean $=3.82$, S.D. $=0.70$ ).

Overall, tourists' demand for agrotourism in Ban Mor Village, Sam Sung District, Khon Kaen Province is at the high level (Mean $=4.10$, S.D. $=0.13$ ), with each aspect from the highest level to the lowest level shown in table 2.

Table 2: Summary of tourists' demand in seven aspects of agrotourism in Ban Mor Village, Sam Sung District, Khon Kaen Province

\begin{tabular}{lccc}
\hline Items & $\bar{x}$ & S.D. & Interpretation \\
\hline Accessibility & 4.42 & 0.25 & highest \\
Attitudes & 4.20 & 0.34 & high \\
Attractions & 4.13 & 0.29 & high \\
Accommodations & 3.90 & 0.34 & high \\
Activities & 3.84 & 0.32 & high \\
Amenities & 4.18 & 0.33 & high \\
Advertising & 4.05 & 0.39 & high \\
\hline
\end{tabular}

Table 2 shows that tourists' demand for agrotourism in Ban Mor Village, Sam Sung District, Khon Kaen Province in terms of accessibility is at the highest level (Mean $=4.42$, S.D. $=0.25$ ) while attitudes (Mean $=4.20$, S.D. $=0.34$ ), attractions $($ Mean $=4.13$, S.D. $=0.29)$, accommodations (Mean $=3.90$, S.D. $=0.34)$, activities (Mean $=3.84$, S.D. $=0.32)$, amenities (Mean $=4.18$, S.D. $=0.33)$, and advertising $($ Mean $=4.05$, S.D. $=0.39)$ are all at the high level.

\subsection{Guidelines to improve agricultural areas for the development of agrotourism in Ban Mor Village, Sam Sung District, Khon Kaen province.}

In the focus group discussion, ten experts, which included academics, tourism entrepreneurs, representatives of involved public organizations and local philosophers proposed guidelines to improve the potential for agrotourism in Ban Mor Village, Sam Sung District, Khon Kaen Province, as detailed below:

(1) Improve Homestay in Ban Mor Village according to the Homestay standard in Thailand

Accommodations relate to tourism attractions and enhanced destinations. In terms of agricultural villages, Homestay is the appropriate type of lodging to support tourism. Staying at Homestay and participating in host farmer's activities will bring tourists new experiences and help them to understand more about the farmers and local culture. Therefore, Ban Mor Village should officially establish and improve Homestay, according to the Homestay standard in 
Thailand. This will help to ensure the quality of agrotourism in Ban Mor Village.

(2) Improve facilitates to respond to tourists' demands

Public utilities should be considered in tourism development. Improved access to Ban Mor Village is something that is necessary and urgent. Better road conditions and clearly labeled signposts to the destination will help tourists arrive to Ban Mor Village conveniently. Water supply and electricity should be funded by involved public organizations to facilitate the tourists.

Furthermore, Ban Mor Village is well known for its local organic agricultural products which are healthy for consumers. Therefore, local cuisine with its healthy ingredients will add value and quality to agrotourism in Ban Mor Village.

(3) Promotion of agrotourism in Ban Mor Village

Nowadays, the Internet offers a rich abundance of information and resources for travelers searching for tourism destinations. It is also convenient and easy to access. Therefore, the Internet is one of the most popular channels to promote tourism destinations. At present, there is no website about agrotourism in Ban Mor Village. So, it is necessary to establish an official website to promote agrotourism in Ban Mor Village which would be taken care of by the Village Community Committee. This website should be designed in the Thai and English languages and should include a brief history of the village, agrotourism activities, accommodations and a map of the village. Keeping the agrotourism information up-to-date is important to ensure reliability with tourists.

In addition to that, brochures or booklets about agrotourism in Ban Mor Village should be created to increase the channel of approach to tourists. These brochures or booklets should be placed at travel agencies, airports and bus stations in Khon Kaen province.

(4) Establish a local agricultural learning center

A local agricultural learning center is the place to keep, preserve and share local history, and local wisdom. Ban Mor Village applies the Sufficiency Economy Philosophy as the fundamental concept for farmer livelihood. This philosophy focuses on economic development in a step-by-step process to attain sustainable development in Thailand's rural areas. It is necessary to introduce this concept to tourists, especially international tourists, to enhance their awareness of the local social-culture in Ban Mor Village.

A tourist souvenir zone should be arranged to show local agricultural products such as chili paste and chili powder, the recommend dishes of Ban Mor Village.

\section{Conclusion}

In this study, the researchers studied tourists' opinions and demands for agrotourism and guidelines to improve the agriculture area to develop agrotourism in Ban Mor Village, Sam Sung District, Khon Kaen province. Quantitative and qualitative methods were applied. The results show that overall tourists believed that organic agrotourism had a positive impact on the local community by giving increasing support to the economic community. Tourists' demand for agrotourism in Ban Mor Village, Sam Sung District, Khon Kaen Province in terms of accessibility is at the highest level while attitudes, attractions, accommodations, activities, amenities, and advertising are all at the high level. Appropriate guidelines were proposed to improve agrotourism in Ban Mor Village, Sam Sung District, Khon Kaen province. These include 1) improving Homestay in Ban Mor Village according to the Homestay standard in Thailand 2) improving facilitates to respond to tourists' demand 3) promoting agrotourism in Ban Mor Village and 4) establishment of a local agricultural learning center in Ban Mor Village.

\section{Acknowledgement}

The authors would like to thank the Bank for Agriculture and the Agricultural Co-operative (BAAC) for providing the funding to support this research.

\section{References}

Arroyo, C.G., Barbieri, C., \& Rich, S.R. (2013). Defining agritourism: A comparative study of stakeholders' perceptions in Missouri and North Carolina. Tourism Management, 37, 39 - 47. Retrieved from http://dx.doi.org/10.1016/j.tourman.2012.12.007.

Buhalis, D. (2000). Marketing the competitive destination of the future. Tourism management 21, 97 - 116. Retrieved from http://dx.doi.org/10.1016/S0261-5177(99)00095-3.

Chalapati, S. (2008). Sufficiency Economy as a Response to the Problem of Poverty in Thailand. Asia Social Science 4(7), 3-6. 
Retrieved from http://www.ccsenet.org/journal/index.php/ass/article/viewFile/1362/1326.

Department of Tourism. (2013). Statistics of tourist in Northeastern of Thailand. Retrieved from www.tourism.go.th.

Evans, N. J., \& Ilbery, B. W. (1989). A conceptual framework for investigating farm based accommodation and tourism in Britain. Journal of Rural Studies, 5, 257-266.

Ely, P.A. (2013). Selling Mexico: Marketing and tourism values. Tourism Management Perspectives, 8, 80 - 89. Retrieved from http://dx.doi.org/10.1016/j.tmp.2013.07.003.

Flanigan, S., Blackstock, K. \& Hunter, C. (2014). Agritourism from the perspective of providers and visitors: a typology-based study. Tourism Management, 40, 394-405. Retrieved from http://dx.doi.org/10.1016/j.tourman.2013.07.004

Goodwin, H. \&Francis, J. (2003). Ethical and responsible tourism: Consumer trends in the UK. Journal of Vacation Marketing, 9(3), 271284. Retrieved from http://dx.doi.org/10.1177/135676670300900306.

Halfacree, K. (1993). Locality and social representation: space, discourse and alternative definitions of the rural, Journal of Rural Studies, 9(1), 23-37. Retrieved from http://dx.doi.org/10.1016/0743-0167(93)90003-3.

Kuo, N.W. \& Chiu, Y.T. (2006). The assessment of agritourism policy based on SEA combination with HIA, Land use policy 23, 560 570. Retrieved from http://dx.doi.org/10.1016/j.landusepol.2005.08.001.

Kumbhar, V. M. (2009). Agro-tourism: Scope and Opportunities for the farmers in Maharashtra. Indiastat, September-October 2009. Retrieved from http://ssrn.com/abstract=1550170.

Leiper, N. (1995). Tourism Management.

Melbourne: RMIT press.

Lopez, E.P. \&Garcia, F.J.C. (2006). Agrotourism, sustainable tourism and Ultraperipheral areas: The Case of Canary Islands. Revista de turismo y Patrimonio Cultural, 4(1), 85-97. Retrieved from www.pasosonline.org/Publicados/4106/PS060106.pd.

Maetzold J. (2002). Nature-Based Tourism \& Agritourism Trends:Unlimited Opportunities. Retrieved from www.kerrcenter.com/ publications/2002_proceedings/agritourism.pdf.

Mongsawad, P. (2010). The philosophy of the Sufficiency Economy: A contribution of the theory of Development. Asia Pacific Development, 17(1), 123 -143. Retrieved from http://www.unescap.org/pdd/publications/apdj_17_1/5_Mongsawad.pdf.

Morrison, A.M. (2013). Marketing and management tourism destination. London: Routledge.

Ollenburg, C. \& Buckly, R. (2007). Stated economic and social motivation of farm tourism operators. Journal of Travel Research, 45(4), 444 - 452. Retrieved from http://dx.doi.org/10.1177/0047287507299574.

Ritson, C. \& Oughton, E. (2006). Food Consumers and organic agriculture. In L. Frener \& H. van Trijp (eds). Understanding consumers of food products. Cambridge: Woodhead Publishing Ltd, pp $254-272$.

Sam Sung District Agricultural Extension. (2012). Organic farm in Ban Mor village, Sam Sung district, Khon Kaen province. Retrieved from http://sumsung.khonkaen.doae.go.th/image/safe\%20vegetable/safe\%20vegetable1.htmTew, C. \& Barbiere, C. (2012). The perceived benefits of agritourism: the provider's perspective. Tourism Management, 33(1), 215 - 224. Retrieved from http://dx.doi.org/10.1016/j.tourman.2011.02.005.

Walley, K.E., Custance P.R., \& Parsons S.T. (2009). Controversies in Food and Agricultural Marketing: The Consumer'sView. In A. Lindgreen, M.K. Hingley, \& J.Vanhamme (Eds), The Crisis of Food Brands. Sustaining safe, Innovative and Competitive Food Supply (pp. 197-219). Burlington: Gower Publishing Limited

Wang, S., Bickle, M. \& Harrill, R. (2009). Residents' attitudes toward tourism development in Shangdong, China. International Journal of Cultural, Tourism and Hospitality research, 4(4), 327 - 339. Retrieved from http://dx.doi.org/10.1108/17506181011081505

Wicks, B. \& Merrett, C. (2003). Agritourism: an economic opportunity for Illinois. Rural Research Report, 14 (9),1-8. Retrieve from http://www.iira.org/pubs/pubRedirect.asp?publD=577.

Williams, J. \& Lawson, R. (2001). Community issues and resident opinions of tourism. Annals of tourism research, 28(2), 269-290. Retrieved from http://dx.doi.org/10.1016/S0160-7383(00)00030-X.

World Tourism Organization. (2007). A Practical Guide to Tourism Destination Management. Madrid: World Tourism Organization.

$\mathrm{Xu}$, J.B. (2010). Perception of tourism products. Tourism Management, 31, 607-610. Retrieved from http://dx.doi.org/10.1016 /j.tourman.2009.06.011.

Yamane, T. (1973). Statistics: an introductory analysis (3rd ed). New York: Happer and Row Publisher.

Yang, Z., Cai, J., Sliuzas,R. (2010). Agro-tourism enterprises as a form of multi-functional urban agriculture for peri-urban development in China. Habitat International 34(4), 374 - 385. Retrieved from http://dx.doi.org/10.1016/j.habitatint.2009.11.002.

Zoto, S., Qirici, E., Polena, E. (2013). Agrotourism - A sustainable development for rural area of Korca. European Academic Research, 1(2), 209 - 223. Retrieved from www.euacademic.org/UploadArticle/15.pdf. 